CIUDAD Y TERRITORIO

ESTUDIOS TERRITORIALES

ISSN(P): 1133-4762; ISSN(E): 2659-3254

Vol. LII, № 206, invierno 2020

Págs. 823-840

https://doi.org/10.37230/CyTET.2020.206.07

CC BY-NC 4.0

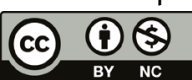

\title{
¿Habitantes o visitantes? El impacto del alquiler vacacional en el mercado de vivienda en Sevilla
}

\author{
Jaime Jover-BÁEZ $Z^{(1)}$ \\ Luis BerRaquero-Díaz (2)
}

(i) Centro de Estudios de Posgrado, City University of New York. ${ }^{(2)}$ Grupo de Investigación Social y Acción Participativa, Universidad Pablo de Olavide.

RESUMEN ${ }^{1}$ : El desarrollo turístico en destinos urbanos españoles ha sido excepcional en tiempos recientes. Sevilla es un caso paradigmático, superando los tres millones de visitantes, gracias entre otros factores a una mayor oferta de alojamiento turístico. Dentro de la misma, destaca el rápido crecimiento del alquiler vacacional: Airbnb y Homeaway se han convertido en actores principales en un corto lapso de tiempo, ofertando un número de plazas casi parejo a los establecimientos tradicionales. Simultáneamente, los precios de venta y alquiler convencional han crecido en los últimos años. Este artículo aborda el impacto del alquiler vacacional sobre el mercado inmobiliario como parte del proceso de turistificación.

PALABRAS CLAVE: Alquiler vacacional; Vivienda; Turistificación; Sevilla.

Recibido: 22.11.2019; Revisado: 04.05.2020

Correo electrónico: jover@gc.cuny.edu; NºRCID: https://orcid.org/0000-0002-1796-1655:

Correo electrónico: luisberraquero@gmail.com; No ORCID: https://orcid.org/0000-0001-9902-5141

Los autores agradecen los comentarios y sugerencias realizados por los evaluadores anónimos, que han contribuido a mejorar y enriquecer el manuscrito original.

${ }^{1}$ Este artículo fue escrito entre la primavera y el otoño de 2019, antes de la pandemia mundial del Covid-19 y la subsecuente crisis económica, que ha afectado particularmente al sector turístico. A pesar de que el contexto ha cambiado radicalmente, el trabajo sigue teniendo relevancia en tanto que las estrategias económicas y políticas de promoción turística, apuntan al deseo de volver a la situación previa a la pandemia que, precisamente por las consideraciones de este trabajo, tendría que repensarse. Ante la necesaria reconstrucción económica, creemos que nuestras conclusiones pueden servir a las instituciones públicas y privadas para plantear un cambio de modelo que, sin desdeñar los beneficios que produce el turismo, incorpore sus vulnerabilidades, sea consciente de los procesos de turistificación sobre el mercado de la vivienda como el estudiado y se tomen las medidas para mitigar los impactos de potenciales crisis en el futuro. 


\title{
Residents or visitors? The impact of vacational rental on the housing market in Seville
}

\begin{abstract}
Tourism development has been extraordinary in Spanish urban destinations. Seville is a paradigmatic case, breaking the record of 3 million visitors thanks to, among others, the enlargement of tourist accommodations. This increase has been especially prominent in short-term holiday rentals. Airbnb and Homeaway have become key players in a brief lapse of time, offering almost as many tourist beds as traditional lodgings, such as hotels and hostels. Simultaneously, housing prices (selling and long-term rentals) have rapidly grown in the past few years. Therefore, we focus on the impact of short-term rentals on the housing market, which is one of the realms where touristification unfolds.
\end{abstract}

KEYWORDS: Short-term rentals; Housing; Touristification; Seville.

\section{Introducción}

\subsection{Justificación, hipótesis y objetivos}

I alquiler vacacional está de moda. Cada año viajan más personas a lo largo y ancho del planeta, y cada vez son más quienes eligen esta tipología de alojamiento turístico para disfrutar de sus vacaciones. La irrupción del alquiler vacacional ha alterado la dinámica del sector turístico, compitiendo con los alojamientos tradicionales en las estancias de corta duración. Sevilla, con un turismo que bate récords anualmente, es una de las ciudades donde más se ha extendido el fenómeno. En 2018, Lonely Planet eligió a la capital andaluza como el mejor destino turístico urbano del mundo, mientras que en 2019 el rotativo inglés The Guardian la recomendó como una de las cinco mejores para visitar (DuNFORD, 2019). El éxito del turismo en Sevilla, que en 2018 y 2019 alcanzó los tres millones de turistas, va en paralelo al de Andalucía, que superó los 30 millones (PÉrez, 2019). La especialización en el sector turístico de las economías andaluza y sevillana no es nueva; sin embargo, el peso adquirido y las consecuencias que se derivan de esta actividad sí constituyen una novedad y merecen un especial escrutinio. Andalucía arrastra una posición de marginalidad socioeconómica desde el siglo XIX, que se agravó a lo largo del XX (ARENAS, 2015), y que en la actualidad configura un territorio dependiente, con una economía extractiva fundamentada en abastecer productos primarios y con escasa capacidad de atraer valores monetarios (Delgado \& al., 2014). La situación reproduce la posición de dependencia de Andalucía y perpetúa el desequilibrio socio-económico con respecto a otras zonas del Estado y de la Unión Europea.

El tradicional modelo turístico de sol y playa andaluz se ha completado con el aumento del turismo cultural, habiendo crecido su peso en Sevilla.
La capital andaluza evidencia cómo una economía urbana, coincidiendo con la profunda crisis financiera, apuesta por el desarrollo turístico y sus ramificaciones en el sector inmobiliario en el contexto del capitalismo transnacional. Así, cabe destacar el elevado número de hoteles de cadenas multinacionales que están abriendo, amén de los fondos de inversión que compran inmuebles residenciales para destinarlos al alquiler vacacional (PAREJO, 2018; GENIZ, 2018), cuya gestión normalmente corre a cargo de agencias profesionales, que hacen negocio intermediando entre huéspedes y anfitriones (Roelofsen \& MinCA, 2018). La iniciativa privada complementa a una política de marketing que ha sido muy agresiva a la hora de promocionar la ciudad como destino. A la amplia oferta cultural fundamentada en el patrimonio, se han añadido las estrategias de tematización -2018 fue el año Murillo, 2019 el año del $5^{\circ}$ centenario de la vuelta al mundo de Magallanes-, o las de convertirse en ciudad de congresos, que tiene su mejor ejemplo en la Cumbre Mundial del Turismo en abril de 2019. Este macro evento fue contestado por movimientos sociales, vecinales y ecologistas de distintas capitales europeas, agrupadas en la red SET (Sur de Europa ante la Turistificación).

Conforme ha ido creciendo la actividad turística en las aglomeraciones urbanas, sobre todo en el sur europeo post-crisis, ha ido aumentando el malestar social. La movilización se ha centrado en denunciar la turistificación, que se define como el proceso de apropiación, tanto físico como simbólico, de un territorio específico por el uso turístico, desplazando a otras actividades, transformando los tejidos social, comercial, asociativo o identitario y generando conflictos por el derecho al descanso. En el plano de la vivienda, la turistificación se identifica con la comercialización a través del alquiler turístico, generando un incremento de la rentabilidad con respecto al alquiler convencional localizado en determinadas zonas, aumentando los precios en el mercado inmobiliario y sustituyendo el uso residencial, lo que genera 
problemas de convivencia. Si bien es cierto que la administración local se afana por remarcar que en la ciudad no se vive un proceso de turistificación (BAREA, 2019), se hace evidente la existencia de una problemática general en torno a la cuestión turística (Jover \& al., 2018) y específica sobre la vivienda, que se ilustra por ejemplo en la campaña municipal «Sevilla llena, todos ganamos», en la que el consistorio quiere comprar o alquilar viviendas vacías para destinarlas a protección oficial (AyUntAMIENTo DE SEVILLA, 2018a).

El objetivo principal de la investigación es analizar una de las consecuencias más denunciadas de la turistificación: cómo el alquiler vacacional hace subir los precios en el mercado de la vivienda, prestando especial atención a su comportamiento espacial en la ciudad hispalense. La hipótesis apunta a que, en determinados barrios del centro histórico, así como en el arrabal de Triana, la concentración del alquiler vacacional estaría provocando: i) el aumento de los precios, de la compra-venta y especialmente del arrendamiento convencional y, como consecuencia; ii) una potencial expulsión de vecinos de esas zonas. Para ello, tras la exposición metodológica, el artículo sitúa el debate del alquiler turístico entre la gentrificación y la turistificación. A continuación, se contextualizan los marcos de producción y regulación a escala estatal y andaluza, atendiendo a las interrelaciones entre las esferas urbanística, turística y de vivienda, una cuestión elemental dado que muestra el papel que las instituciones han jugado para facilitar la expansión de aquellos procesos. Finalmente, se aborda el estudio empírico sobre el caso de Sevilla, poniendo el foco en la distribución y la evolución reciente del alquiler turístico.

\subsection{Metodología y fuentes}

El artículo se fundamenta en tres tipos de análisis. En primer lugar, se realiza un estudio de la bibliografía reciente, documentos de prensa e informes técnicos sobre el mercado inmobiliario y sus efectos en las ciudades, que se pone en relación con trabajos específicos sobre alquiler turístico, gentrificación y turistificación, centrándonos en el caso de Sevilla. En segundo lugar, se relaciona el panorama legislativo y las políticas en materia de arrendamientos, de urbanismo y de turismo en tres escalas: Estado español,

\footnotetext{
2 Cabe remarcar la falta de colaboración y transparencia del Ayuntamiento de Sevilla, al que se le cursaron dos peticiones de datos turísticos, ambientales e inmobiliarios que fueron desoídas.
}

Comunidad Autónoma y municipios. Esto se realiza sobre un lapso temporal amplio, porque el contexto actual no se puede comprender en toda su complejidad sin atender a la evolución del marco de regulación. En último lugar, se analizan distintos repositorios estadísticos públicos y privados relacionados con la vivienda y con el alquiler turístico. En lo que se refiere a los datos sobre el mercado de la vivienda, se cruza la información con otras fuentes de datos tales como tamaño de la población; número y tipo de la vivienda -a partir del censo de 2011, que fue elaborado a través de una estimación, y del reciente Plan Municipal de la Vivienda de Sevilla-; afluencia y plazas turísticas; construcción y stock de viviendas; o el precio de estas y el alquiler turístico ${ }^{1}$. Sobre las fuentes de datos del mercado de la vivienda y del alquiler vacacional cabe hacer algunas puntualizaciones.

No existen datos públicos desagregados por distritos o barrios de la evolución de precio de compra y de alquiler, con excepción de los desarrollados por algunas comunidades autónomas, como Cataluña ${ }^{2}$. Los datos que disponemos son de los portales inmobiliarios Idealista y Fotocasa. El primero ofrece una serie de la evolución de precios de venta y alquiler desde 2008, aunque no está desagregada por distritos en Sevilla. Sus informes de evolución de precios de venta y alquiler están elaborados a partir de las actualizaciones de precios que los propietarios de viviendas realizan sobre los inmuebles anunciados en su portal. Las viviendas cuyos precios están fuera de la desviación típica del precio medio por metro cuadrado para cada distrito o municipio se excluyen de tales informes. El índice inmobiliario de Fotocasa, por su parte, es el único que ofrece datos acerca de la evolución de los precios de venta y alquiler desagregados por distritos, solamente desde 2014. Si bien el arco temporal es breve a efectos analíticos, coincide con la llegada del fenómeno del alquiler vacacional a Sevilla. La información también proviene de las viviendas anunciadas en este portal. Fotocasa, como también Idealista, garantizan la fiabilidad de la muestra incorporando un mínimo de observaciones, alcanzando un $95 \%$ de confianza y un error inferior al $10 \%$ del valor asignado. Ahora bien, es preciso tomar estos datos con precaución, en tanto que, en determinados casos, puede que las partes implicadas, arrendador y arrendatario, negocien un precio final de venta o alquiler distinto al establecido inicialmente en las páginas web.

\footnotetext{
${ }^{3}$ La aprobación del Real Decreto-Ley $7 / 2019$, de 1 de marzo, quiere paliar esta situación estableciendo la creación de sistemas de índices de referencia del precio del alquiler anualmente agregados a varias escalas de análisis.
} 
En relación a los datos del alquiler turístico, se ha realizado un análisis de concentración espacial (Kernel) con la estadística del Registro de Turismo de Andalucía. Ahora bien, es preciso mencionar que tiene carencias, en tanto que los datos registrados no coinciden con los anuncios ofertados en las webs de Airbnb y Homeaway (ahora denominada Vrbo). Estas dos, junto con Booking, son las principales comercializadoras de esta tipología de alojamiento en nuestro país, cuyos datos se obtienen a través de DataHippo 4 , por tanto, los anuncios no tienen una localización exacta, porque ambas empresas recomiendan a sus anfitriones no geolocalizar sus propiedades con exactitud. En este sentido, también puede existir cierta agregación, si bien se considera que no es significativa dada la dificultad de tener una misma propiedad en las dos plataformas al mismo tiempo -lo que estas mismas desaconsejan-, por ejemplo, debido al solapamiento en los tiempos de reserva. Un argumento en contra sería la profesionalización de la gestión, que se observa en los últimos años en Sevilla, aunque no al nivel de las grandes ciudades turísticas europeas, donde este tipo de empresas cada vez tiene mayor peso en el mercado.

\section{Alquiler turístico: entre la gentrificación y la turistificación}

La proliferación de los alquileres turísticos ha sido notable en una mayoría de destinos, teniendo especial incidencia en contextos urbanos. En ciudades de interior y que atraen turismo cultural, el incremento se ha focalizado en los centros históricos que, además de soportar una mayor carga turística, en muchos casos ya habían sufrido procesos de gentrificación. LeEs \& al. (2016) afirman que estos procesos de transformación urbana comparten patrones comunes de fundamento neoliberal reproducidos a lo largo y ancho del mundo junto con otras particularidades, que dependen de los contextos estatal o municipal. Así, la turistificación tiene una vertiente planetaria, especialmente si atendemos al incremento anual de los viajeros -cada vez más en destinos urbanos- que ofrece la Organización Mundial del Turismo. De hecho, gentrificación y turistificación se han entendido como procesos indistintos (HieRnAuX \& GonzÁlez, 2014), en tanto que podrían compartir características comunes en diferentes partes del mundo, apareciendo el concepto gentrificación turística (Gotham, 2015; Cocola-GANT,
2018). No obstante, la amplia flexibilidad que se le atribuye a la gentrificación es difícil asimilarla desde la perspectiva turística, porque no hay un reemplazo de una población de menor poder adquisitivo por otra de mayor, sino una sustitución de la función residencial por la turística. La turistificación, además, hace referencia a un proceso que afecta a diferentes dimensiones de lo urbano y con distintos ritmos e intensidades: el tejido comercial, el espacio público, la sociabilidad, el consumo de recursos naturales o la imagen simbólica de la ciudad proyectada y (auto)percibida. En cualquier caso, gentrificación y turistificación son la punta de lanza de un desarrollo geográfico desigual, que se hace evidente en el mercado de la vivienda. La expansión del alquiler turístico, con especial fuerza en el sur de Europa, ha impulsado trabajos en este sentido (VIVES-MIRÓ \& RuLLÁN, 2017; Cocola-GANT \& GAGO, 2019). La gentrificación y la turistificación, además, comparten una consecuencia: el desplazamiento de población de menor estatus y poder económico en determinados barrios, abundando en la injusticia socio-espacial.

Vincular turistificación y desplazamiento supone, amén de las interrelaciones con los procesos de gentrificación clásica y transnacional (JOVER \& DíAz-PARRA, 2019), incorporar el alquiler vacacional a la ecuación. WACHSMUTH \& WeISLER (2018) teorizan sobre una brecha de renta particular para este modelo de alojamiento turístico, que se capitalizaría en mucho menos tiempo que la tradicional enunciada por CLARK (1987). Esta tesis vincula la diferencia entre el valor existente actual del suelo y del entorno urbano con el valor potencial si se destina a otros usos, como el alquiler vacacional. Así, la brecha de renta a corto plazo supondría que los propietarios de una vivienda no tendrían que esperar a un estado de abandono del inmueble o del medio ambiente urbano en el que se encuentra para obtener una mayor plusvalía de las rentas del suelo, sino que bastaría con su explotación como alquiler turístico (YRIGOY, 2019). MoreLL (2019) incide en una idea similar argumentando que la devaluación necesaria para capitalizar la brecha no solo proviene del entorno construido, sino que también existe en el régimen de tenencia de la vivienda: el inquilinato, especialmente el que reside en viviendas de protección oficial, sirve de elemento de depreciación urbana. La principal condición para realizar este diferencial de renta es que el alquiler vacacional sea rentable, lo que sucede en áreas urbanas centrales de ciudades turísticas, que normalmente son también históricas

\footnotetext{
${ }^{4}$ Proyecto colaborativo de web scrapping: https://datahippo.org/es/
} 
en nuestro contexto, y cuya transformación en espacios privilegiados se ha constatado en los últimos años (Álvarez, 2015; Díaz-PARRA, 2010).

En el caso de las ciudades españolas, Airbnb apunta que solo representan el $5 \%$ de la oferta total de alojamientos turísticos (FÀBREGA, 2018). Además, en un reciente informe, la Comisión Nacional de Mercados y la Competencia (en adelante CNMC) defendía la importancia de los alquileres turísticos para la mejora de la competitividad de los destinos. En el documento del regulador estatal se alaban los efectos positivos de esta tipología de alojamiento, sin obviar aquellos negativos -adjetivados como posiblesen el mercado de la vivienda. Entre ellos, se recoge el incremento del precio de la vivienda, especialmente en determinadas zonas urbanas, aunque se esgrime que no existen evidencias definitivas que indiquen este particular. No obstante, el propio informe reconoce que

«la localización geográfica es una variable fundamental en el mercado de alojamiento turístico y los operadores tienen incentivos a concentrarse [...] cerca de paisajes naturales o centros culturales-históricos» (CNMC, 2018a: 50)

señalando cómo su distribución espacial en la ciudad es un factor clave en el impacto sobre el mercado de la vivienda.

En esta tipología de alojamiento, la relación entre aspectos turísticos, urbanísticos e inmobiliarios se hace muy estrecha. El mismo informe las entiende como viviendas de uso turístico, remarcando que, de haber problemas en el mercado, estarían compartidos con todo el sector inmobiliario. En la lógica de la economía colaborativa, el alquiler vacacional es una cesión temporal de una vivienda, por lo que esta no pierde su función residencial, de ahí el nombre elegido por la CNMC y otras administraciones. Se trata de un tema controvertido, porque en última instancia dependerá del tiempo que estas viviendas estén destinadas a alquiler vacacional, esencialmente si es completo a lo largo del año, o parcial -y en este caso, cuántas semanas o meses-. La cuestión de la duración del alquiler, así como la concentración de propiedades en pocas manos (Coyle \& Yeung, 2016), son temas centrales a la hora de profundizar sobre el grado de colaboración en este tipo de economías. La administración estatal no es ajena a los potenciales problemas, $y$ el Real Decreto-Ley 7/2019, de medidas urgentes en materia de vivienda y alquiler, expone que:

«el incremento de los precios del mercado de la vivienda ha sido particularmente intenso en entornos territoriales de fuerte dinámica inmobiliaria caracterizados por una mayor actividad tu- rística desarrollada sobre el parque de viviendas existente» (BOE $n^{\circ} 55$, de 5 de marzo de 2019).

Todo ello se produce en un contexto nacional donde el régimen de tenencia del arrendamiento es poco común, a diferencia de lo que ocurre en otros países del entorno europeo.

La escasa preferencia por el alquiler se debe a la cultura de la propiedad, promovida durante décadas. España tiene un parque de viviendas sobredimensionado y mal repartido fruto de una serie de políticas que, lejos de garantizar el acceso a este derecho, han generado un proceso especulativo asociado a la construcción (RoDRíGUEZ, 2010). A esto se añade una baja inversión pública en ayudas a la compra y al alquiler, siendo el país de la Organización para la Cooperación y el Desarrollo Económicos (OCDE) -junto con Chipre y Malta- que menos porcentaje del PIB destina a subsidios en vivienda: en 2015 tan solo el $0.01 \%$ (datos de la OCDE). En las principales ciudades españolas, la demanda de arrendamiento es generalmente mayor que la oferta, lo que provoca que los precios sean por lo general más altos y, a largo plazo, muchas familias consideren más rentable la adquisición a través de un crédito bancario. Así, se retroalimenta la compra-venta y se estimula el mercado hipotecario, alentado por el estatus social de la vivienda en propiedad, lo que provoca que solo el $22 \%$ de la población viva de alquiler. En paralelo, de todos esos hogares, el $42 \%$ utiliza más del $40 \%$ de sus ingresos para sufragar el arrendamiento, mucho más que en el resto de Europa (datos de Eurostat). Todo ello en un mercado cada vez más financiarizado, donde muchos jóvenes no pueden emanciparse y cuando se ha producido una desposesión sin precedentes durante la crisis de 2008.

\section{La evolución de la vivienda y del turismo en la ciudad española y andaluza}

\subsection{Planificación urbanística y la vivienda como negocio}

La producción de ciudad y de destinos turísticos ha ido de la mano en la historia reciente de España, desde el aperturismo de la dictadura a partir de los años sesenta del siglo pasado (MuRRAY, 2015). Ya en los ochenta, la transición hacia una democracia liberal supone un giro definitivo en la economía española hacia los sectores de la construcción y de los servicios en la reestructuración económica y la convergencia con la Comunidad Económica Europea. La asunción de la lógica neoliberal unida a la inversión europea en infraestructuras y a la alta especialización en el 
ámbito inmobiliario-financiero y el turismo provocaron un ciclo expansivo que terminó en una primera burbuja (NAREDO, 1996). Tras esta crisis se profundizó en los instrumentos jurídico-políticos que afianzaron la neoliberalización de la economía, cuyo período alcista acabaría en un nuevo escenario disruptivo en 2007. A ello contribuyó la Ley 6/1998, sobre Régimen de Suelo y Valoraciones (BOE $n^{\circ} 89$, de 14 de abril de 1998) junto con otras normas posteriores que la modifican y rectifican en una línea similar en tanto que buscaban abaratar el precio de la vivienda liberalizando el suelo bajo el axioma que todo es urbanizable salvo lo que está claramente protegido (BURRIEL, 2008; VIVES-MIRó \& RULLÁN, 2014). Así, se generó un caldo de cultivo que desembocó en una fuerte especulación durante los primeros años del siglo XXI, convirtiendo a la vivienda en una mercancía de la que extraer jugosas rentas a corto plazo (GARCíA \& JANOSCHKA, 2016), un proceso que en la costa -con una intensa relación con el turismo- fue calificado de «tsunami urbanizador» (GAJA, 2008). En este período, la función pública del urbanismo pasó en ocasiones a un segundo plano en aras de las plusvalías producidas por la actividad constructiva, lo que se observa en la sobredimensión de las previsiones de crecimiento demográfico que en los planes justifican numerosos desarrollos (VINUESA \& MARTín, 2013).

La planificación se contrajo y, como consecuencia, el modelo territorial se vio perjudicado en un sinfín de casos porque se carecían de criterios que lo definieran con nitidez. El desarrollo de infraestructuras de transporte facilitó el desembarco de visitantes, a lo que también contribuyó la intensificación de las estrategias de promoción turística desde los noventa, cada vez más asociadas a políticas culturales en los espacios urbanos centrales, con un mayor número de atractivos patrimoniales (TroITIÑO, 1998). Todo ello ha confluido en la actualidad en un contexto de competición entre metrópolis donde el mercado libre sustituye al regulador público en la gestión de la ciudad, hablándose de urbanismo empresarial (HARVEY, 2001) o concesional en el caso español (GAJA, 2015). Los efectos de este modelo de crecimiento sustentado en el sector de la construcción se solaparon con aquellos que gestaron la crisis financiera global en 2008 , hundiendo el mercado de la vivienda y provocando un repunte generalizado de las tasas de desempleo, que en zonas como Andalucía fue todavía más acuciante (FERNÁNDEZ \& CRUZ, 2013). Entre los resultados más crudos de la crisis en relación al mercado de la vivienda se encuentra el drama de los desahucios, que afectó con especial incidencia en zonas urbanas (MÉNDEZ \& PLAZA, 2016; VIVEs-MiRó \& RuLLÁN, 2017).

En el pico más alto de la serie en 2006, España alcanzó el récord de 597.632 viviendas libres construidas, 20.000 más que 2007. Este último año, junto a 2008, marcaron el tope del precio de la vivienda libre, por encima de los $2.000 € /$ $\mathrm{m}^{2}$. En total, en los tres años entre 2006 y 2008 se construyeron en España casi dos millones de viviendas, incluidas las de protección oficial. Como se observa en la FIG. 1, esto supuso que aumentara el excedente hasta casi las 650.000 unidades en 2009. A partir de ese año, el precio medio (que recoge las viviendas libres y sociales) cayó hasta alcanzar el mínimo de la serie en $2014\left(1.285,5 € / \mathrm{m}^{2}\right)$. La FIG. 1 también muestra cómo esta caída la sufre el precio de la vivienda libre, mientras que la de protección oficial se mantuvo en toda la serie entorno a los $1.000-1.100 € / \mathrm{m}^{2}$.

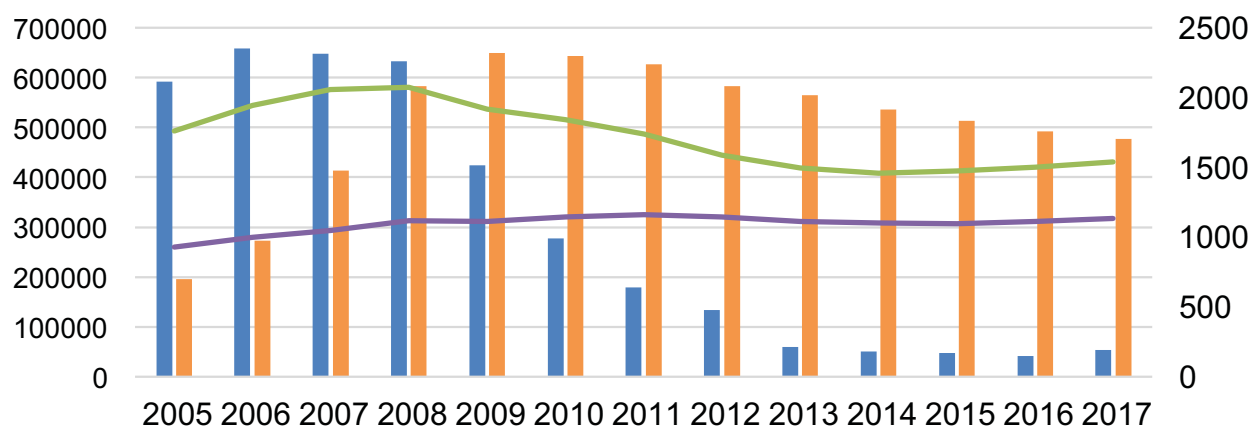

Nuevas viviendas

Stock de viviendas

—Vivienda libre $\left(€ / \mathrm{m}^{2}\right)$

-Vivienda protegida $\left(€ / \mathrm{m}^{2}\right)$

/ Evolución de la construcción y stock en relación al precio de la vivienda (libre y protegida) en España (2005-2017).

Fuente: Elaboración propia a partir de MINISTERIO DE FOMENTO. 


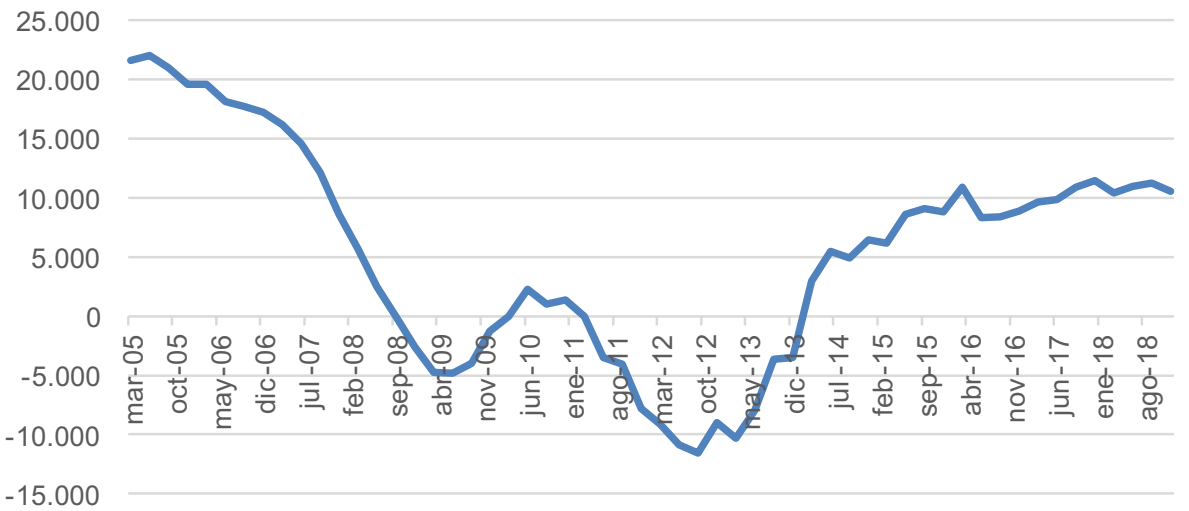

FIG. 2/ Rentabilidad anual de la vivienda (\%) en España con base en la revalorización del precio de la vivienda y la rentabilidad bruta del alquiler.

Fuente: elaboración propia a partir de BANCO DE ESPAÑA.

Finalmente, el stock se ha ido reduciendo progresivamente hasta quedar por debajo del medio millón de unidades, mientras que la construcción sigue baja, si bien a partir de 2017 se observa una ligera recuperación, especialmente de la vivienda libre. Por su parte, la construcción de vivienda pública es marginal, con menos de 5.000 unidades anuales desde 2013. Cabe resaltar que la construcción de este tipo de vivienda en el contexto de la burbuja tampoco consiguió contener los precios al alza (ETXEZARRETA \& al, 2012). Al contrario, los precios siguieron subiendo, si bien aquellas contribuyeron a que muchas familias pudieran acceder a una vivienda bajo unas condiciones en las que no habrían podido de no ser por estas políticas públicas. Además del ligero incremento del precio de la vivienda que se observa recientemente, existen otros indicadores. Por ejemplo, las transacciones de compra-venta de vivienda de segunda mano ante notario han alcanzado en marzo de 2018 una cifra (147.366.000) que no se daba desde julio de 2006 (datos del Banco de España).

Así, la Fıg. 2 recoge la evolución sobre cuán rentable es la inversión en vivienda a partir de la suma de la rentabilidad del alquiler y de la plusvalía que se obtendría de la venta de la vivienda. En esta variable se deja notar con mayor fuerza la llegada de la crisis, alcanzando la rentabilidad de la vivienda un mínimo en la serie en junio de 2012: $-11,5 \%$. A partir de 2013 , la rentabilidad se recupera a un ritmo similar al de caída unos años antes, para estabilizarse a partir de 2016. Dicho momento coincide, de un lado, con la modificación de la Ley de Arrendamientos Urbanos (LAU) por la Ley 4/2013, de 4 de junio, de medidas de flexibilización y fomento del mercado de alquiler de viviendas (BOE $n^{\circ} 134$, de 5 de junio de 2013), que otorga una mayor seguridad al arrendador en el alquiler convencional y vincula el alquiler temporal a la normativa turística. De otro lado, se adopta la Ley $8 / 2013$, de 26 de junio, de rehabilitación, regeneración y renovación urbanas (BOE $n^{\circ} 153$, de 27 de junio de 2013), que se centra en dirigir la extracción de plusvalías resultantes de la urbanización hacia la intervención en la ciudad consolidada mediante distintas estrategias, entre las que destaca la flexibilización en la firma de convenios urbanísticos (DE LA CRUZ, 2014; GAJA, 2015). Como se observa, la salida de la crisis en España está supeditada a la reactivación del negocio inmobiliario, con una novedad: el foco ya no se centra solamente en la expansión urbana, sino también en la rehabilitación, donde gana peso aquella asociada al turismo.

\subsection{El difícil engranaje entre vivienda, urbanismo y turismo}

¿Qué cuota de la recuperación del mercado inmobiliario que se observa desde 2013 está relacionada con el turismo? Responder a esta pregunta no es fácil, especialmente en ámbitos urbanos. Allí donde el turismo se ha desarrollado con más velocidad, las administraciones no han sido ajenas al avance de los alquileres turísticos. Por un lado, las Comunidades Autónomas han ejercido su competencia y han legalizado, con criterios similares, esta tipología de alojamiento (CNMC, 2018a). Por otro lado, algunos ayuntamientos se han visto en la necesidad de ordenar el fenómeno para hacerlo compatible con la planificación urbanística. La diferencia estriba en que esta última regulación ha puesto sobre la mesa algunos de los efectos perniciosos del 
alquiler turístico, por ejemplo, en relación al acceso a la vivienda por parte de la población local. En consecuencia, los ayuntamientos han previsto medidas de control, que en la mayoría de casos se han limitado al cumplimiento de las normas urbanísticas estructurales, como la separación de los usos residenciales y terciarioshoteleros. De esta forma, Barcelona aprobó el Plan Especial Urbanístico de Alojamientos Turísticos que zonificaba todos los alojamientos en cuatro zonas con un régimen específico (BLANCORomero \& al., 2018), mientras que San Sebastián tomaba una medida similar, en su caso en tres zonas. Sin embargo, esta última ordenanza, que desarrolla al plan general de la ciudad vasca, ha sido recurrida ante los tribunales por la CNMC, al entender como restricciones aquella zonificación, además de la exigencia, entre otros, de la creación de un censo sobre licencias en aras de una mayor transparencia (CNMC, 2018b).

En el caso andaluz, la Ley 7/2002, de Ordenación Urbanística, en adelante LOUA (BOJA n 154 , de 31 de diciembre de 2002), también recoge la calificación del suelo urbano en diferentes usos como uno de los criterios estructurales que toda planificación urbanística requiere. La LOUA se atribuye las competencias no solamente en la creación de la nueva ciudad, sino en la ordenación de la existente, y por eso prevé distintas disposiciones acerca de la rehabilitación y renovación urbanas. En este particular no queda claro cómo se articula con la anteriormente referida Ley 4/2013 (FIG. 3), especialmente si tenemos en consideración que la ordenación territorial y urbana son competencias de las Comunidades Autónomas en la Constitución española. A estas también pertenecen las competencias en turismo, y así queda reflejado en los distintos estatutos de autonomía, como el andaluz. Del desarrollo de este particular se encarga la Ley 13/2011, del Turismo de Andalucía (BOJA n 255, de 31 de diciembre de 2011), que persigue "una nueva cultura [turística] basada en la sostenibilidad», señalando que «la ordenación del turismo tiene una significativa dimensión territorial, ambiental y paisajística». Sobre esta base, y habida cuenta de la modificación de la LAU por la Ley 4/2013, la Junta de Andalucía dispuso el Decreto 28/2016, de las viviendas con fines turísticos (BOJA n ${ }^{\circ} 28$, de 11 de febrero de 2016). Además de la seguridad pública y la protección del consumidor, la norma se justifica en «las situaciones de intrusismo y competencia desleal» que podrían estar afectando a otras tipologías de alojamiento más consolidadas, como los hoteles. Además, el legislador andaluz afirma en la exposición de motivos que:

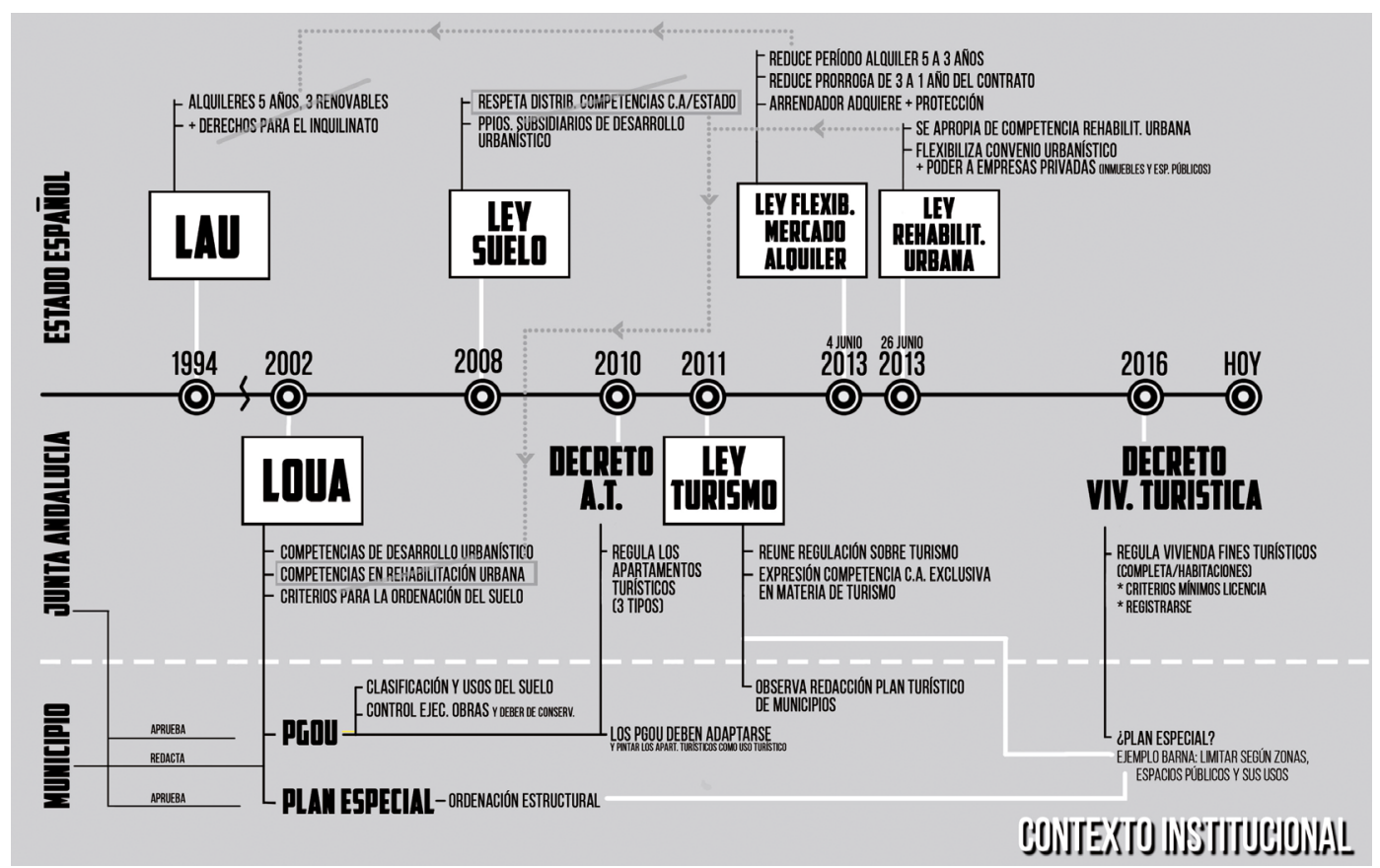

FIG. 3/ Infografía que vincula a tres escalas las formas de relación de la legislación en materia de urbanismo, vivienda y turismo. 
"no se puede obviar la importancia del impacto y la incidencia que este tipo de actividad y, en concreto, este tipo de alojamiento produce sobre el territorio, la comunidad donde se integra y su repercusión directa sobre la convivencia vecinal".

De esta forma, la política turística andaluza asume el concepto de vivienda turística, y exige una serie de estándares mínimos de habitabilidad (determinados por la licencia de ocupación), requisitos propios de establecimiento turístico (hoja de reclamaciones, promoción, limpieza, etc.) o la obligatoriedad de inscripción en el Registro de Turismo de Andalucía en pos de evitar el intrusismo. Ahora bien, el Decreto tiene posibles lagunas, amén de la incompatibilidad entre urbanismo y turismo. Como señala Román, (Román, 2018: 596597), existe «un conflicto entre la naturaleza de estos alojamientos -servicios turísticos, esto es, uso turístico del suelo- y el suelo sobre el que se asientan [las viviendas] de uso residencial». El autor advierte acerca de esta contradicción y la necesidad de resolverla, además de añadir otras dos ideas clave. En primer lugar, la inexistencia del límite temporal al uso turístico de la vivienda, lo que es incoherente con tal concepto, en tanto que puede haber propiedades que se conviertan en alquileres turísticos permanentes perdiendo su condición residencial. En segundo lugar, los criterios menos exigentes que se demandan en comparación con otros alojamientos, sensiblemente los apartamentos turísticos, que en Andalucía hacen referencia a todo un inmueble con este uso, con criterios de promoción, limpieza o seguridad.

\section{Turismo y vivienda en Sevilla: dos caras de una misma moneda}

\subsection{La consolidación de Sevilla como destino turístico}

El origen de Sevilla como destino turístico está estrechamente vinculado a su desarrollo urbanístico. La Exposición Iberoamericana de 1929 fue clave en la reestructuración de la ciudad: expansión urbana, diseño de espacios monumentales o reinvención del barrio de Santa Cruz (DíAz-PARRA, 2016). Este último se convertiría, junto a los bienes declarados Patrimonio Mundial porla Unesco en 1987 (Alcázar, Archivo de Indias y Catedral) en la atracción turística principal de Sevilla. Una segunda intervención urbanística con la Exposición Universal de 1992 como excusa terminaría por poner los cimientos para el despegue turístico. Más allá de la operación de desvío del Guadalquivir para que sus crecidas no afecten al suelo urbano o la rehabilitación de edificios emblemáticos, este macro-evento sirvió para la construcción de nuevos alojamientos hoteleros e infraestructuras de transporte, destacando la estación de ferrocarril y el aeropuerto. Desde entonces, el turismo ha ido ganando cada vez más importancia. La crisis ha provocado una fuerte especialización en el sector, que se ha convertido en el principal motor de la economía urbana, lo que se evidencia en varios indicadores.

La FIG. 4 recoge la evolución de los establecimientos y las plazas turísticas -en tres categorías-

\begin{tabular}{|c|c|c|c|c|c|c|c|c|}
\hline \multirow{2}{*}{ Año } & \multicolumn{2}{|c|}{$\begin{array}{l}\text { Hoteles, hostales } \\
\text { y pensiones }\end{array}$} & \multicolumn{2}{|c|}{ Apartamentos turísticos } & \multicolumn{2}{|c|}{ Alquiler turístico } & \multicolumn{2}{|c|}{ Total } \\
\hline & Est. & Plazas & Est. & Plazas & Est. & Plazas & Plazas & $\%$ hot \\
\hline 2008 & 159 & 16748 & 518 & 1248 & $\mathrm{~s} / \mathrm{d}$ & $\mathrm{s} / \mathrm{d}$ & 17996 & 93,07 \\
\hline 2009 & 163 & 17313 & 525 & 1248 & $\mathrm{~s} / \mathrm{d}$ & $\mathrm{s} / \mathrm{d}$ & 18561 & 93,28 \\
\hline 2010 & 168 & 17987 & 591 & 1508 & $\mathrm{~s} / \mathrm{d}$ & $\mathrm{s} / \mathrm{d}$ & 19495 & 92,26 \\
\hline 2011 & 173 & 18016 & 666 & 1806 & $\mathrm{~s} / \mathrm{d}$ & $\mathrm{s} / \mathrm{d}$ & 19822 & 90,89 \\
\hline 2012 & 188 & 18622 & 772 & 2215 & $\mathrm{~s} / \mathrm{d}$ & $\mathrm{s} / \mathrm{d}$ & 20837 & 89,37 \\
\hline 2013 & 196 & 19319 & 543 & 1737 & $\mathrm{~s} / \mathrm{d}$ & $\mathrm{s} / \mathrm{d}$ & 21056 & 91,75 \\
\hline 2014 & 192 & 19668 & 859 & 2703 & $\mathrm{~s} / \mathrm{d}$ & $\mathrm{s} / \mathrm{d}$ & 22371 & 87,92 \\
\hline 2015 & 211 & 20787 & 964 & 2713 & $\mathrm{~s} / \mathrm{d}$ & $s / d$ & 23500 & 88,46 \\
\hline 2016 & 217 & 21453 & 1111 & 3652 & 1322 & 6231 & 31336 & 68,46 \\
\hline 2017 & 212 & 21589 & 1776 & 3612 & 2405 & 11369 & 36570 & 59,03 \\
\hline 2018 & 218 & 22140 & $s / d$ & $s / d$ & 3897 & 18486 & 40626 & 54,50 \\
\hline
\end{tabular}

FIG. 4/ Establecimientos y plazas turísticas en Sevilla. 
en la última década. Los hoteles, hostales y pensiones han sido fundamentales para la consolidación del turismo, y no han parado de crecer en el último decenio. El único año de la serie en el que los establecimientos de este tipo se reducen es 2014, sin que ello suponga una merma en el número de plazas, volviendo a crecer todavía más rápido a partir del año siguiente -hasta alcanzar el récord histórico de plazas hoteleras en 2018-. Por su parte, los apartamentos turísticos (de una, dos y tres llaves) también han crecido durante la crisis, con especial intensidad a partir de 2014 , cuando se registran 316 más, es decir, casi 1.000 plazas más con respecto al año anterior. Los establecimientos de este tipo han seguido creciendo, si bien las plazas se estabilizan, aunque no se disponen de los datos más recientes. Finalmente, el alquiler turístico comienza a contabilizarse tras la aprobación del Decreto anteriormente mencionado en febrero de 2016, creciendo exponencialmente desde entonces. La regularización supone que, en 2018 , las plazas de alquiler turístico sean ligeramente inferiores que las de los hoteles, hostales y pensiones, cuyo peso relativo se ha reducido casi en un $40 \%$ en diez años. Entre las tres tipologías se contabilizan más de 40.000 plazas oficiales, sin tener en consideración los alquileres turísticos no registrados. Si la oferta turística ha crecido, también lo ha hecho la demanda, circunstancia que se observa relacionando el número de plazas estimadas (solo de establecimientos hoteleros) con el de pernoctaciones estimadas (en los mismos establecimientos), tomando 2003 como base 100 (FIG. 5). Con intervalos, plazas y pernoctaciones se mantienen parejas hasta 2013, cuando las pernoctaciones crecen a un ritmo más elevado que las plazas hoteleras. El incremento tanto de la oferta como de la demanda evidencia el reciente éxito de Sevilla como destino turístico.

Las razones que explican esta mayor afluencia turística son variadas y van desde las estrategias de marketing hasta el contexto geopolítico en el

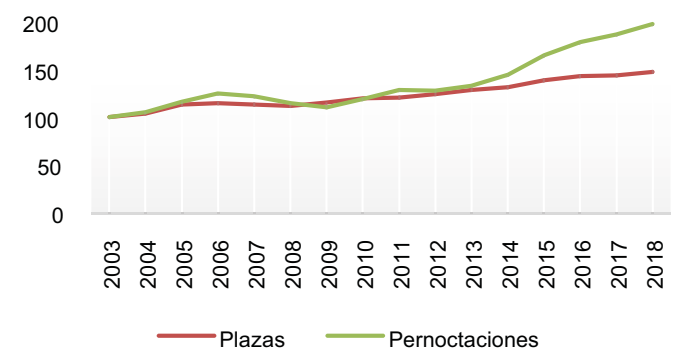

FIG. 5/ Evolución del número de plazas y de pernoctaciones en establecimientos hoteleros en Sevilla (2003-2018). base 100.

Fuente: Elaboración propia a partir de Encuesta de Ocupación Hotelera, Instituto NACIONAL DE EstadisticA.
Mediterráneo, pasando por la reactivación del turismo nacional cuyas cifras tocaron fondo entre 2009 y 2010 . Y, más allá de las cifras, entre las consecuencias principales se encuentran dos con un marcado carácter geográfico. El incremento de la oferta y la demanda ha llevado a una expansión espacial de la actividad. El turismo en Sevilla ha dejado de estar concentrado en el barrio de Santa Cruz y sus alrededores inmediatos, y se ha extendido hacia otras partes del centro histórico y también a Triana, donde se ha ampliado la zona de Gran Afluencia Turística (AyuntAmiento de SeVILLA, 2018b). En paralelo, conforme las zonas centrales ganan peso, las diferencias socio-espaciales han ido ampliándose: entre los segmentos de barrios más ricos -como los turísticos-y los más pobres hay entre 35.000 y $40.000 €$ anuales de renta media (datos de Indicadores Urbanos 2017, Instituto Nacional de Estadística).

\subsection{El desarrollo reciente del mercado de la vivienda}

En buena medida, gran parte de las desigualdades en Sevilla tienen su fundamento en la vivienda. La geografía de la ciudad ha tenido históricamente un eje de segregación social más o menos diferenciado entre el suroeste y el noroeste. La distribución socio-laboral con mayor capacidad se ha concentrado en los barrios del oeste y del sur, con ramificaciones hacia el este (Nervión o Santa Clara), ubicándose los barrios de corte obrerista en los sectores norte y este principalmente, salvo excepciones como Bellavista o el Polígono Sur (DíAz-PARRA, 2010). A esta distribución se le ha de sumar la dinámica centro-periferia, que se ha ampliado en los años de la crisis. En relación a la vivienda, el partido judicial de Sevilla fue el segundo con mayor número de ejecuciones hipotecarias entre 2007 y 2013, cuando se ejecutaron 9.453 desahucios, por delante de ciudades más pobladas como Barcelona o Valencia (datos del Consejo General del Poder Judicial). A todo ello cabe sumar los llamados "desahucios invisibles", o la expulsión de inquilinos ante la imposibilidad de hacer frente a subidas del precio del alquiler muy por encima del incremento del Indice de Precios de Consumo (IPC) a la hora de renovar el contrato.

La evolución del precio medio anual de la vivienda en alquiler en Sevilla, en comparación con el Estado, presenta valores diferentes en función de las fuentes de datos. Según Idealista, el precio medio del alquiler en Sevilla alcanzó los $9,48 € / \mathrm{m}^{2}$ en 2018, llegando casi a igualar los niveles a los que llegó en 2008. No obstante, 
todavía estaría por debajo de la media estatal, que alcanza su mínimo en 2014 y a partir de 2016 supera a la sevillana debido al peso de Barcelona o Madrid $\left(16,38 € / \mathrm{m}^{2}\right.$ y $15,31 € / \mathrm{m}^{2}$ respectivamente de precio medio anual de la vivienda en alquiler en 2018). Asimismo, en Sevilla se observan unas grandes diferencias entre barrios, algunos con un precio medio anual muy por debajo de la media española. Por su parte, Fotocasa ofrece en 2018 unos valores menores para Sevilla $\left(8,40 € / \mathrm{m}^{2}\right)$, que aun así está por encima de la media del conjunto del Estado $(8,25$ $€ / \mathrm{m}^{2}$ ). Atendiendo a la evolución de precios por distritos en la FIG. 6, se distinguen tres áreas muy por encima de la media de la ciudad y el global del Estado: Triana, Casco Antiguo y Los Remedios. El incremento del alquiler medio anual en estos distritos se produce con mayor intensidad coincidiendo con la irrupción de los alquileres vacacionales y la mayor rentabilidad que rinden a los propietarios. A grandes rasgos, tomando como indicador una vivienda de $60 \mathrm{~m}^{2}$ en Triana, donde el arrendamiento medio anual es $9,89 € / \mathrm{m}^{2}$ en 2018, el precio mensual de un alquiler de larga duración se sitúa por debajo de los $600 €$. En una búsqueda no exhaustiva en Airbnb de alquileres turísticos de tamaño similar en temporada media, se encuentran alojamientos que oscilan entre los 80 y $100 €$ al día de media. Además de la diferencia entre ambos mercados de alquiler, la FIG. 6 recoge las disimetrías de precios entre Triana y Cerro-Amate o Este-Alcosa-Torreblanca, que ilustra cómo la segregación socio-espacial sigue siendo una realidad.
Si el precio del alquiler en Sevilla toca suelo en 2014, según Idealista la vivienda en venta lo hace en 2015, registrando valores mínimos: $1.774 € /$ $\mathrm{m}^{2}$. La cifra, no obstante, es elevada si se compara con la media nacional (FIG. 1). Desde 2015, la tendencia crece rápidamente, alcanzando los $1.937 € / \mathrm{m}^{2}$ en 2018 -y superando la barrera de los $2.000 € / \mathrm{m}^{2}$ en los primeros meses de 2019-, aunque aún muy lejos de los $3.000 € / \mathrm{m} 2$ que alcanzó en 2007. De hecho, en el momento de irrupción de la crisis, las familias dedicaban de media el $42,31 \%$ de sus ingresos a pagar la hipoteca en el área metropolitana de Sevilla, mientras la media en Andalucía era del 35,67\% (AYUNTAMIENTO DE SeVILLA, 2009). Desafortunadamente no existen datos actualizados al respecto. Sí contamos con los datos de Fotocasa sobre el precio de venta de vivienda por distritos, donde se observan zonas que casi han recuperado los niveles pre-crisis. Tal es el caso del centro histórico, que superó los $3.000 € / \mathrm{m}^{2}$ en febrero de 2019 , con una tasa de crecimiento del $11,1 \%$ en 2018 . Los distritos que le siguen son Nervión y Triana con $2.464 € / \mathrm{m}^{2}$ y $2.419 € / \mathrm{m}^{2}$ respectivamente. El incremento de precios viene acompañado de una política municipal de vivienda que no satisface a la demanda: por ejemplo, en 2008 se completaron 3.461 viviendas protegidas en la ciudad -entre asignación y alquiler-, mientras que en 2016 -último dato disponible-, la cifra cae a 232 (datos de la Consejería de Fomento de la Junta de Andalucía). Con todo, la recuperación del precio de la vivienda enajenada, como la arrendada, tiene una clara diferenciación espacial, en un gradiente con el pico

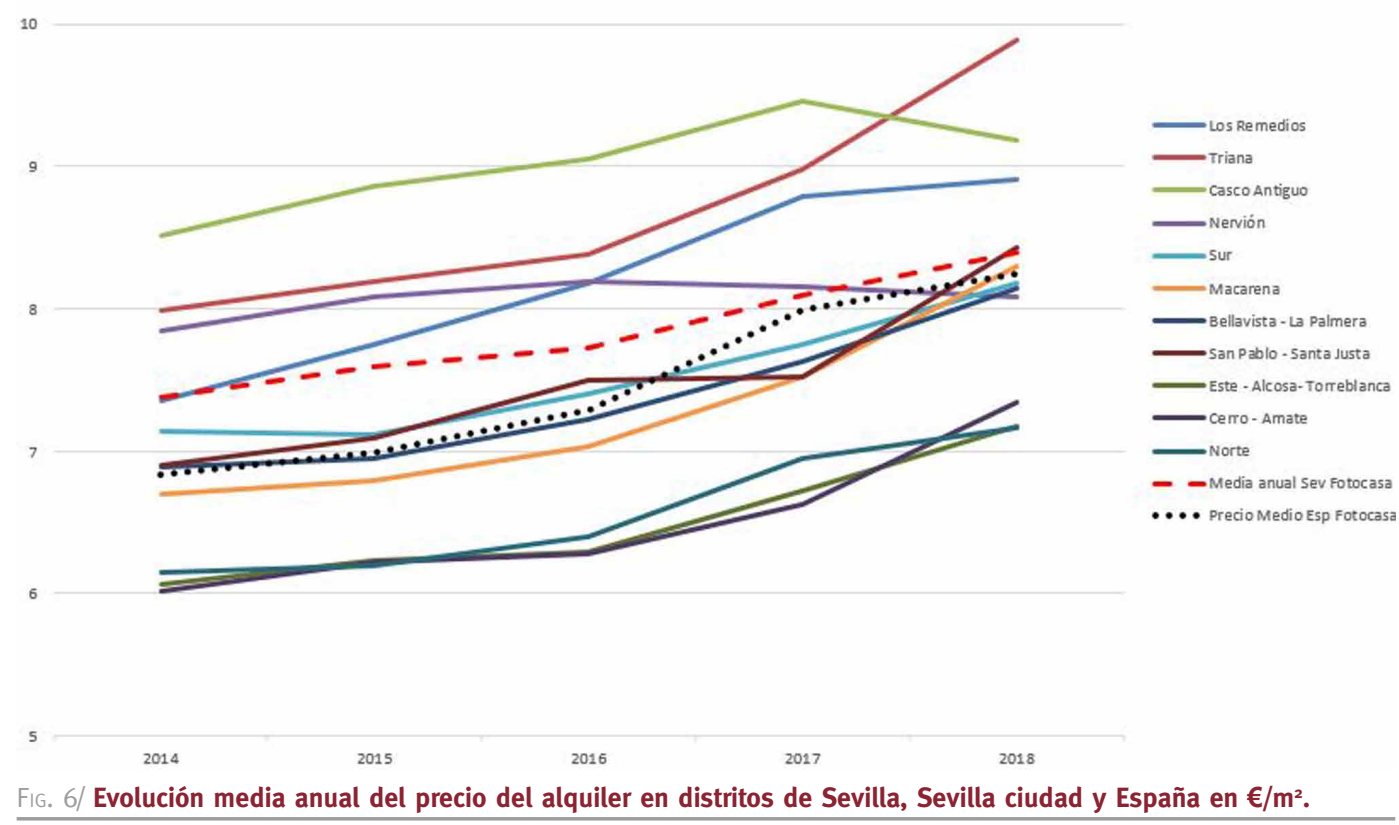

Fuente: Elaboración propia a partir de datos de Fotocasa. 
máximo en zonas centrales que se diluye con distinta intensidad hacia la periferia.

\subsection{El impacto del alquiler turístico en el mercado de la vivienda}

¿Hasta qué punto incide el alquiler vacacional en este crecimiento del precio de venta y alquiler de la vivienda? Para responder a la pregunta se mide el impacto del alquiler turístico mediante el análisis de dos variables: evolución y distribución. Esta última marca la pauta, puesto que haciendo un análisis de densidad sobre el total de los alquileres turísticos -registrados y no registrados- a finales de 2018 , se aprecia una fuerte concentración: casi el $75 \%$ de los anuncios está en el centro histórico y en el casco antiguo del distrito Triana, al otro lado del río (FIG. 7). Se trata de dos zonas que apenas representan el $9,2 \%$ de población en una ciudad con 688.711 habitantes en la actualidad ( $\mathrm{y}$ un millón y medio si incluimos su corona metropolitana). Este porcentaje se ha mantenido estable en los últimos años, si bien la tendencia es descendente. Desde 2012 se observa cómo el casco antiguo y Triana pierden población a un ritmo similar al conjunto de la ciudad (datos del padrón municipal).
La FIG. 7 no solamente permite diferenciar una fuerte polarización en la localización del alquiler turístico, también da cuenta de la elevada concentración dentro del centro histórico. Antes de poner el foco en estos barrios, cabe realizar un análisis de la evolución reciente del alquiler turístico en términos absolutos. La Fig 4 reflejaba cómo en diciembre de 2016, tras unos meses de obligatoriedad en la inscripción de estos alojamientos, en Sevilla se contabilizan 1.322. Un año después, a finales de 2017, la cifra asciende hasta 2.405 , repartidos entre 2.237 viviendas y 168 habitaciones. Es decir, en ese momento, la vivienda completa constituye oficialmente el $93 \%$ del alquiler turístico. Al año siguiente, el alquiler turístico según el Registro de Turismo de Andalucía asciende a 3.897 unidades, repartidas entre 3.594 viviendas completas y 303 habitaciones, por lo que las propiedades completas se mantienen en el $92,2 \%$, ofertando el $93,5 \%$ de las plazas totales. Por barrios, la Fig 8 da cuenta del incremento en el alquiler turístico registrado, que destaca en los barrios de la Alfalfa y la Feria.

Sin embargo, los datos reales con los que contamos son diferentes. A finales de 2017 hay un desfase de más de 4.500 anuncios entre la cifra oficial y la real, en tanto que el número total

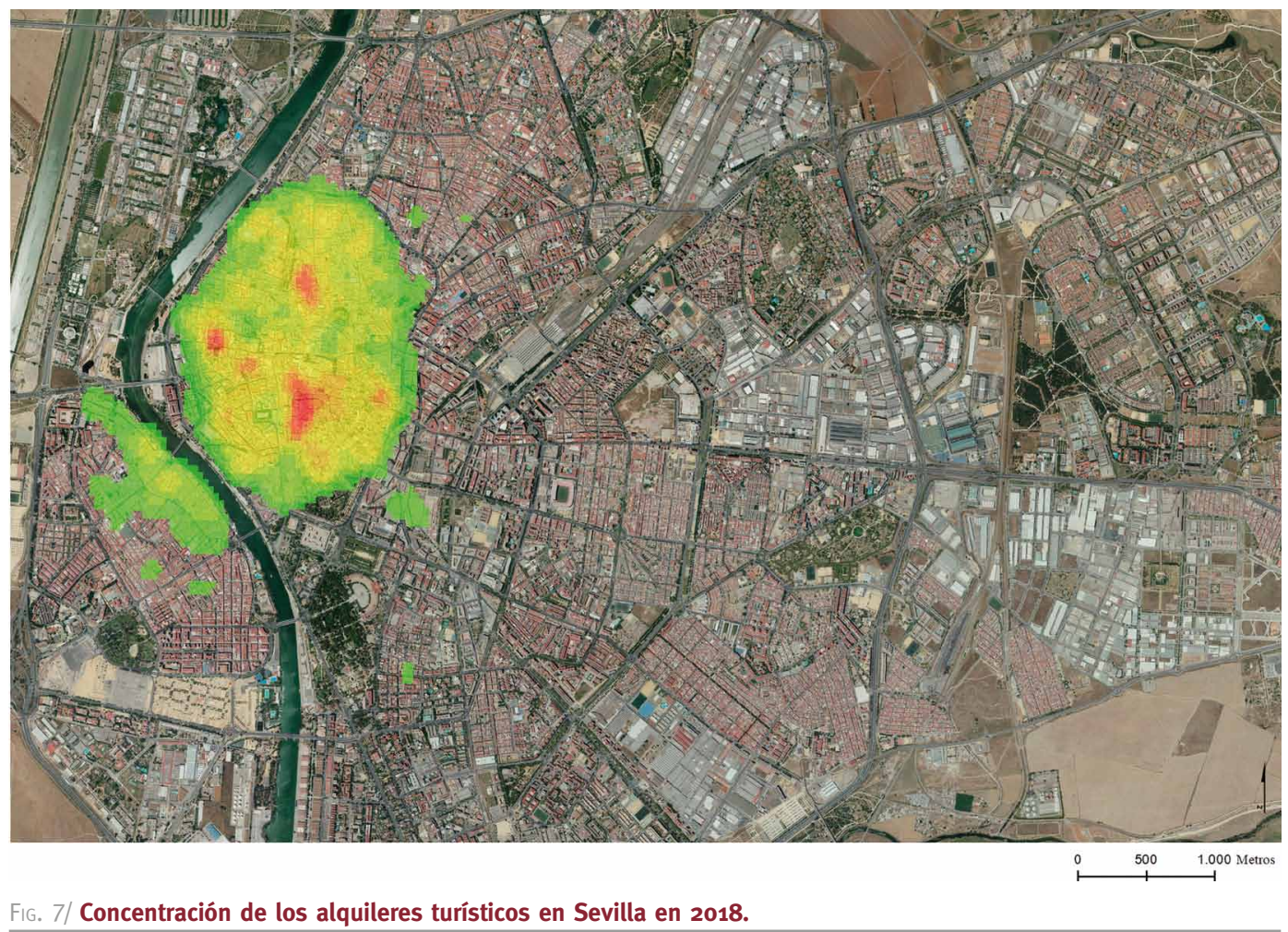

Fuente: Elaboración propia a partir de datahippo.org y Datos Espaciales de Referencia de Andalucía. 
asciende a 7.089 , entre 5.674 propiedades en Airbnb y 1.415 en Homeaway. Esta última solo oferta viviendas completas, mientras que la primera alberga más variedad: el $70 \%$ son viviendas, el $29,5 \%$ habitaciones privadas y un marginal $0,5 \%$ habitaciones compartidas. No obstante, de las 20.811 plazas ofertadas, la gran mayoría (17.188) están en viviendas completas. Al respecto, si tomamos los datos conjuntamente con los de Homeaway, de las 7.089 propiedades listadas, 5.377 ofertan una vivienda completa, el $75,8 \%$. La brecha entre los datos oficiales y reales se amplía en 2018 hasta más de 5.500 anuncios: Airbnb concentra 7.423 y Homeaway 2.131, para un total de 9.554 , lo que se aproxima a la estimación de 10.000 alquileres turísticos que había hecho el consistorio (Ayuntamiento de Sevilla, 2018c). Ello a pesar del acuerdo entre la Junta de Andalucía y Airbnb por el que en septiembre de 2018 desaparecieron más de 20.000 anuncios que no tenían número de registro (Durán, 2018). En Airbnb en 2018, de nuevo, la mayor parte de la oferta son viviendas completas $(71,3 \%)$, reduciéndose las habitaciones privadas $(28,1 \%)$ y las compartidas $(0,48 \%)$. En cuanto a las plazas, la tendencia es similar. Si volvemos a tomar los datos de forma conjunta, se observa que en un año las viviendas completas en alquiler turístico crecen hasta el $77,7 \%$ de la oferta. Por tanto, el alquiler vacacional se fundamenta principalmente en la comercialización para uso turístico de viviendas completas.

Centrándonos en los barrios donde se concentra el alquiler vacacional, la FIG. 9 recoge la situación entre 2011, en un contexto previo a la explosión

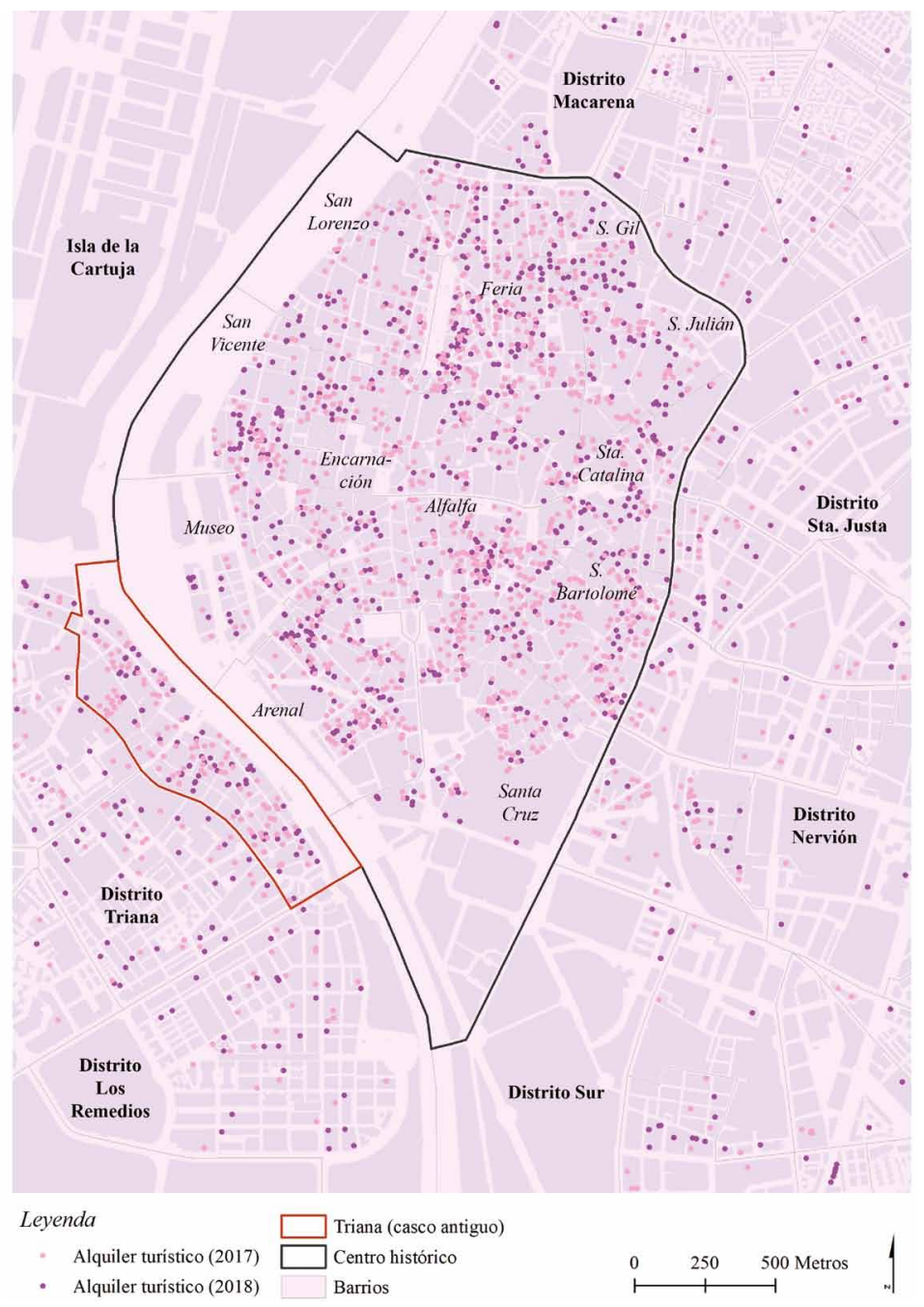

FIG. 8/ Evolución anual (2017-18) de los alquileres turísticos en el centro de Sevilla.

Fuente: Elaboración propia a partir de Registro de Turismo de Andalucía y Datos Espaciales de Referencia de Andalucía. 


\begin{tabular}{lcccccc}
\hline Barrio & $\begin{array}{c}\text { Viviendas } \\
(\mathbf{2 0 1 1})\end{array}$ & $\begin{array}{c}\text { \% viv. vacias } \\
(\mathbf{2 0 1 1})\end{array}$ & $\begin{array}{c}\text { Población } \\
(\mathbf{2 0 1 1})\end{array}$ & $\begin{array}{c}\text { Población } \\
(\mathbf{2 0 1 8})\end{array}$ & $\begin{array}{c}\text { Alquiler } \\
\text { vacacional } \\
(\mathbf{2 0 1 8})\end{array}$ & $\begin{array}{c}\text { \% alquiler } \\
\text { vacacional } \\
(\mathbf{2 0 1 8})\end{array}$ \\
\hline Alfalfa & 4035 & 42,13 & 3805 & 4555 & 1006 & 24,93 \\
\hline Arenal & 4085 & 40,76 & 4190 & 3592 & 638 & 15,62 \\
\hline Encarnación & 3125 & 14,56 & 4680 & 4101 & 578 & 18,50 \\
\hline Feria & 5195 & 28,39 & 7605 & 6351 & 714 & 13,74 \\
\hline Museo & 2935 & 10,39 & 5490 & 5300 & 339 & 11,55 \\
\hline San Bartolomé & 3255 & 24,88 & 4595 & 3659 & 683 & 20,98 \\
\hline San Gil & 3735 & 28,25 & 6120 & s/d & 450 & 12,05 \\
\hline San Julián & 3440 & s/d & 5895 & 6001 & 300 & 8,72 \\
\hline San Lorenzo & 2560 & 20,90 & 5345 & s/d & 386 & 15,08 \\
\hline San Vicente & 3070 & s/d & 4085 & s/d & 407 & 13,26 \\
\hline Santa Catalina & 2605 & 23,22 & 4370 & 4285 & 339 & 13,01 \\
\hline Santa Cruz & 1560 & 12,82 & 2320 & 2369 & 693 & 44,42 \\
\hline Triana & 4090 & 6,36 & 7955 & 7006 & 467 & 11,42 \\
\hline
\end{tabular}

FIG. 9/ Relación entre parque de viviendas, población y alquiler turístico en los barrios centrales de Sevilla.

Fuente: Censo de Población y Viviendas, Instituto Nacional de Estadística; padrón municipal de población y datahippo.org

turística, y 2018, cuando ya se ha producido dicha explosión. En primer lugar, en la relación entre alquiler turístico y población, se observan dos tendencias. En líneas generales, encontramos una pérdida generalizada de efectivos en la mayoría de barrios entre 2011 y 2018 siguiendo la tendencia de la ciudad, siendo más pronunciada en aquellos que concentran mucho alquiler turístico, como San Bartolomé, Triana o Feria. La única excepción es la Alfalfa, donde triunfa el alquiler turístico al mismo tiempo que se observa un incremento poblacional. En segundo lugar, y en relación al parque de viviendas, es interesante observar cómo las zonas con menos alquiler turístico en términos absolutos (Museo, San Julián o Santa Catalina) son barrios muy intervenidos urbanísticamente, en muchos casos con edificaciones en altura de los años setenta y ochenta. Estos barrios también son, junto con Triana, los que tienen un menor porcentaje del parque de vivienda destinado a alquiler turístico. En el lado opuesto, con un alto porcentaje de alquileres vacacionales, se sitúan ámbitos muy turísticos como Santa Cruz y San Bartolomé, donde también se concentran un buen número de hoteles y de conflictos en torno a la actividad (Mercado \& Fernández, 2018). Otro barrio con una fuerte concentración de alquileres turísticos es la Alfalfa, que comprende gran parte de las principales calles comerciales de la ciudad. Posiblemente, esto provocaba que en 2011 fuera la zona con mayor porcentaje de viviendas vacías junto al Arenal que, a diferencia de la Alfalfa, no ha ganado población. Una posible hipótesis para esta estimación, por tanto, está en la transformación de espacio residencial en espacio comercial (Jover, 2019).

En cualquier caso, el aumento del alquiler vacacional no puede haber sido a costa de viviendas vacías exclusivamente. Si se comparan los porcentajes de la FIG. 9, y salvando el lapso temporal, en algunos barrios (Feria, San Bartolomé o San Lorenzo) esta afirmación podría sostenerse. En otras zonas, como Santa Catalina y la Alfalfa, sí cabría afirmar que hay una estrecha relación entre ambas variables, aunque en este último barrio la disponibilidad de vivienda también ayuda a explicar el aumento de población. Por su parte, en otros barrios (Encarnación, Museo o Triana), el alquiler turístico ocupa proporcionalmente más parque de viviendas que aquellas vacías en 2011, lo que sumado al descenso poblacional apunta a una posible sustitución de vecinos por turistas, como también ha señalado otra investigación reciente (JOVER \& DIAZ-PARRA, 2020). Para comprender la relación entre el parque de viviendas y el alquiler turístico también se pueden comparar los datos recientes que ofrece el Plan Municipal de la Vivienda, aunque solamente a escala de distrito. Como se observa en la FIG. 10, las viviendas vacías en el conjunto del Casco Antiguo se reducen entre 2011 y 2017 , a la par que crecen las viviendas principales, una 


\begin{tabular}{lccccccccc}
\hline & \multicolumn{2}{c}{$\begin{array}{c}\text { Viviendas } \\
\text { totales }\end{array}$} & $\begin{array}{c}\text { \% Viviendas } \\
\text { principales }\end{array}$ & $\begin{array}{c}\text { \% Viviendas } \\
\text { secundarias }\end{array}$ & \% Viviendas vacias & $\begin{array}{c}\% \text { Alquiler } \\
\text { vacacional }\end{array}$ \\
\hline Distrito & 2011 & 2017 & 2011 & 2017 & 2011 & 2017 & 2011 & 2017 & 2018 \\
\hline Casco Antiguo & 39890 & 34310 & $67 \%$ & $70 \%$ & $9 \%$ & $18 \%$ & $24 \%$ & $11 \%$ & $17,65 \%$ \\
\hline Triana & 24445 & 24905 & $85 \%$ & $78 \%$ & $8 \%$ & $14 \%$ & $7 \%$ & $8 \%$ & $11,42 \%$
\end{tabular}

0/ Relación entre tipologías de usos residenciales y alquiler turístico en los distritos Casco Antiguo y Triana.

Fuente: Elaboración propia a partir del Censo de Población y Viviendas, InSTITUTO NACIONAL DE ESTADisTICA y Ayuntamiento de SeVilla (2018c).

tendencia inversa a la que se observa en Triana. En el Casco Antiguo, además, esta evolución viene marcada por un descenso del parque de vivienda en números absolutos, que iría en la línea de la transformación de espacio residencial en comercial comentado. Aunque lo realmente interesante es la evolución de las viviendas secundarias, cuya metodología de conteo con respecto al censo de 2011 modifica dicho Plan ${ }^{5}$. En ambos distritos se da un incremento de viviendas secundarias en 2017: en el Casco Antiguo de un $9 \%$ y en Triana de un $6 \%$. Así, sobre el total de las viviendas, las secundarias que contabiliza el Ayuntamiento en 2017 parecen coincidir con los alquileres turísticos en 2018 , lo que apuntaría a un trasvase en el mercado inmobiliario hacia funciones no residenciales y ayudaría a explicar el descenso de la población en ambos distritos.

\section{Conclusiones}

Los datos disponibles señalan que el incremento acelerado del alquiler turístico está teniendo repercusión en el aumento del precio de la vivienda enajenada y arrendada en Sevilla, al coincidir las zonas donde se produce. La turistificación, en tanto que aumento del número de alquileres turísticos, no puede sostenerse exclusivamente en la ocupación para esta finalidad de viviendas vacías. Por el contrario, el rápido aumento de precios del alquiler convencional en el casco antiguo y Triana apunta a una reducción de la oferta de vivienda activa en este mercado. La expectativa de obtener una renta inmobiliaria

\footnotetext{
${ }^{5}$ En el Plan Municipal de Vivienda, las viviendas secundarias se calculan a partir del cruce de datos de propiedades en el registro catastral del Ministerio de Hacienda con los datos de viviendas principales que aparecen como residencia habitual en el padrón municipal. Para excluir a aquellas viviendas que están
}

más elevada y que se capitaliza en un período más corto a través del alquiler vacacional está detrás de esta situación. La teoría de la brecha de renta a corto plazo (WACHSMUTH \& WEISLER, 2018) también explica la velocidad a la que ha crecido el precio de la vivienda enajenada, puesto que los mayores beneficios que se extraen del alquiler turístico reducen el plazo de recuperación de la inversión inmobiliaria en aquellas zonas especialmente turísticas. Asimismo, y por lo general, la regresión demográfica en los barrios más turísticos apunta a un desplazamiento de la población debido a la incidencia de la turistificación en forma de menos vivienda disponible y a un precio más elevado, en lo que también podría tener efectos la conversión de edificios residenciales en hoteles. Las políticas públicas que promueven la rehabilitación de inmuebles, la renovación urbana y el turismo son clave en toda esta transformación.

De la misma forma, cabe hacer precisiones por barrios. En Triana, la Feria o la Encarnación, a la rentabilidad de la vivienda en una zona céntrica se añade el valor que potencialmente puede adquirir si se dedica a la modalidad de alojamiento estudiada. La gentrificación que comenzó en los noventa se solapa con la turistificación actual, siendo que, a pesar de la revalorización de espacios públicos y privados en los primeros años del siglo XXI, el turismo ha venido a ampliar un diferencial de renta que todavía no se había cerrado. Por su parte, en zonas como San Gil, San Julián o Santa Catalina, el menor porcentaje de alquiler turístico puede deberse a una velocidad más lenta a la hora de capitalizar rentas a través de este mercado a diferencia del inmobiliario, que todavía está muy activo. La mayor presencia de inquilinos 
también podría tener efectos, pero necesitamos investigaciones que profundicen en tal sentido. Así, si bien se constata las consecuencias de la turistificación en el mercado inmobiliario, el grado de intensidad y la profundidad del impacto del alquiler turístico son difícilmente cuantificables. Este trabajo utiliza datos de entidades privadas -cuyas cifras difieren y podrían tratar de influir en dicho mercado- porque se carece de datos públicos sobre precios de alquiler y de compraventa de vivienda, que son muy necesarios y con la mayor desagregación posible para evaluar con precisión cuestiones sobre este derecho universal a distintas escalas. Afortunadamente, esta laguna parece que está en vías de ser resuelta. En último término, estos datos son interesantes para tomar en consideración la posibilidad de desarrollar herramientas de control de precios ante contextos abusivos y/o especulativos. La disponibilidad de esta estadística también ayudaría a profundizar sobre el ritmo y la forma en la que se capitaliza la brecha de renta por barrios, una investigación que en el futuro debería complementarse con técnica cualitativas, por ejemplo, mediante entrevistas con informantes cualificados.

Por otra parte, en el campo normativo en Andalucía, el argumento de que el alquiler turístico es una cesión del uso habitual de la vivienda con fines turísticos no se sostiene. Al no prever una limitación temporal de este uso, la legislación andaluza está legitimando el cambio de la función residencial de la vivienda a la comercial en miles de inmuebles en la Comunidad Autónoma, sin conocer cuántos se arriendan un mes y cuántos anualmente. El rápido aumento que se evidencia en Sevilla en tan solo dos años y la falta de atención generalizada a la obligatoriedad de la inscripción -pese a un supuesto acuerdo entre la Junta de Andalucía y Airbnb- sugiere que la gran mayoría se dedican a la actividad turística de forma exclusiva y prolongada en el tiempo. Además, la política turística está condicionando la planificación urbanística, al imponer de facto cambios en la ordenación del suelo urbano, esto es, que una función pública esencial para la convivencia en la ciudad esté siendo socavada por los designios del mercado, modificando el instrumento regulador principal de una ciudad: el Plan General. Que se permita la compatibilidad de usos en un edificio entre el residencial y el hotelero puede terminar con los criterios de zonificación del urbanismo moderno, pero no para permitir más hibridación en las ciudades, sino para ser más excluyentes. Esto es particularmente acuciante en un contexto donde la política de vivienda social se ha reducido a la mínima expresión. Todo ello provoca que la concentración del alquiler turístico esté alimentando la mercantilización del centro histórico al mismo tiempo que perpetúa la geografía de la desigualdad en Sevilla.

El conflicto entre estas políticas autonómicas no es el único que se observa. El Estado central ha sido un agente clave en esta situación al desligar el alquiler vacacional de la norma fundamental sobre arrendamientos urbanos, que es central en la estructura del ordenamiento jurídico especialmente en un país con poca cultura de alquiler. Por todo ello, no existe una solución para atajar esta cuestión, sino varias e, idealmente, coordinadas. Entre ellas podrían estar la vuelta del alquiler vacacional a la $L A U$ y su restricción temporal -entre uno y dos meses, por ejemplo, atendiendo a los días de vacaciones que normalmente tienen las personas trabajadoras-; el reconocimiento de las leyes urbanísticas (la LOUA en Andalucía) como aquellas con competencias para ordenar y gestionar el fenómeno urbano; o la recuperación de una política municipal de vivienda y el fomento de otros regímenes, como las cooperativas de vivienda en cesión de uso. También resulta necesario exigir los mismos requisitos de apertura y explotación a todas las tipologías de alojamientos turísticos, puesto que difícilmente se evita la irregularidad y se fomenta la libre competencia si hay distinciones. Transversal a todo ello está, además, la necesidad de repensar el turismo como actividad monopolística en las economías urbanas, para lo que necesitamos más análisis sobre otras formas en las que la turistificación se despliega, complementado con técnicas cualitativas, y en más ciudades para tener elementos de comparación.

\section{Bibliografía}

Arenas Posadas, C. (2015): Poder, economía y sociedad en el sur. Sevilla, Fundación Centro de Estudios Andaluces.

Álvarez Mora, A. (2015): Políticas de vivienda y exclusividad espacial de clase: controversias en el centro histórico de Valladolid. Ciudad y Territorio. Estudios Territoriales, vol. XVLVII, no. 184, 329-342.

Ayuntamiento de SeVILLA (2009): «Informe socioeconómico y anuario estadístico 2006-2008».

https://www.sevilla.org/servicios/servicio-de-estadistica/archivos/informes/informe-2008 (consulta: 9/5/2019).

- (2018a): «El Ayuntamiento abre la primera convocatoria para la compra de viviendas vacías para fines sociales». 
https://www.sevilla.org/ayuntamiento/alcaldia/comunicacion/noticias/el-ayuntamiento-abre-la-primera-convocatoria-para-la-compra-de-viviendasvacias-para-fines-sociales-con-una-estimacion-detres-millones-de-euros-en-2018 (consulta: 11/11/2018).

- (2018b): «Ampliada la Declaración de Zona de Gran Afluencia Turística a Triana».

https://www.sevilla.org/ayuntamiento/alcaldia/comunicacion/noticias/ampliada-la-declaracion-dezona-de-gran-afluencia-turistica-a-triana (consulta: 10/3/2019).

- (2018c): Avance del Plan Municipal de la Vivienda 2018-2023. Sevilla, Empresa Municipal de la Vivienda de Sevilla.

BAREA, M. (2019, 12 de abril): «El alcalde de Sevilla asegura que en la ciudad no hay turistificación», Diario de Sevilla.

https://www.diariodesevilla.es/sevilla/alcalde-asegura-Sevilla-no-hay-turistificacion 01344766097. html (consulta: 14/4/2019).

Blanco-Romero, A. \& Blázquez, M. \& Cànoves, G. (2018): Barcelona, housing rental bubble in a tourist city. Social responses and local policies. Sustainability, vol. 10, no. 6, 2043. https://doi.org/10.3390/su10062043

BuRRIEL de Orueta, E. (2008): La década prodigiosa del urbanismo español (1997-2006). Scripta Nova, vol. XII, no. 270 (64). www.ub.es/geocrit/sn/sn-270/sn-270-64.htm

CLARK, E. (1987): The rent gap and urban change. Lund, Lund University Press.

Cocola-Gant, A. (2018): Tourism gentrification. En L. Lees \& M. Phillips (eds.): The Handbook of G(2015): Urbanismo concesional. Ciudades. Revista del Instituto Universitario de Urbanística de la Universidad de Valladolid, vol. 18, no. 1, 103-126.

Garcia Pérez, E. \& Janoschka, M. (2016): Derecho a la vivienda y crisis económica: la vivienda como problema en la actual crisis económica. Ciudad y Territorio. Estudios Territoriales, vol. XLVIII, no. 188, 213-228.

GenIz, D. (2018, 6 de octubre): «Inversores nacionales a la caza de la vivienda en Sevilla», Diario de Sevilla, https://www. diariodesevilla.es/sevilla/Inversoresnacionales-caza-vivienda-Sevilla 0 1288371804. html (consulta: 3/2/2019).

GoTHAM, K. (2005): Tourism Gentrification: the case of New Orleans' Vieux Carre. Urban Studies, vol. 42, no. 7, 1099-1121.

Harvey, D. (2001): Espacios del capital. Madrid, Akal.

Hiernaux, D. \& González, C. (2014): Turismo y gentrificación: pistas teóricas sobre una articulación. Revista de Geografía Norte Grande, vol. 58, 55-70.

Instituto NaCional de Estadística (2017): «Indicadores Urbanos 2017. Nota de prensa». https://www.ine.es/prensa/ua 2017.pdf

Jover, J. (2019): Geografía comercial de los centros históricos: entre la gentrificación y la patrimonialización. El caso de Sevilla. Boletín de la Asociación de Geógrafos Españoles, vol. 82, 1-33. http://dx.doi.org/10.21138/bage.2788

JOVER, J. \& al. (2018): Turistización y movimientos urbanos de resistencia: experiencias desde Sevilla. En C. Milano \& J. Mansilla (eds.): Ciudad de vacaciones (pp. 403-437). Barcelona, Pol.len.
JoVer, J. \& DiAz-PARRA, I. (2019): Gentrification, transnational gentrification and touristification in Seville, Spain. Urban Studies. https://doi.org/10.1177/0042098019857585

- (2020): Who is the city for? Overtourism, lifestyle migration and social sustainability. Tourism Geographies. https://doi.org/10.1080/14616688.2020.1713878

Lees, L., Shin, H. \& LóPez, E. (2016): Planetary Gentrification. Cambridge, Polity Press.

Méndez, R. \& PlazA, J. (2016): Crisis inmobiliaria y desahucios hipotecarios en España: una perspectiva geográfica. Boletín de la Asociación de Geógrafos Españoles, n. ${ }^{\circ} 71,99-127$.

Mercado Alonso, I. \& Fernández Tabales, A. (2018): Percepciones y valoraciones sociales del paisaje en destinos turísticos. Análisis de la ciudad de Sevilla a través de técnicas de investigación cualitativas. Cuadernos de Turismo, no. 42, 355-383.

MoRelL, M. (2019): Turismo y diferencial de renta. No hay vacaciones para la lucha de clases. En E. Cañada \& I. Murray: Turistificación global (pp. 309-323). Barcelona, Icaria.

MurRaY, I. (2015): Capitalismo y turismo en España. Del milagro económico a la gran crisis. Barcelona, Alba Sud.

NARedo Pérez, J. M. (1996): La burbuja inmobiliariofinanciera en la coyuntura económica reciente (1985-1995). Madrid: Siglo XXI.

PAREJO, J. (2018, 10 de abril): Hoteles de cinco estrellas: un mercado al alza, Diario de Sevilla, https://www. diariodesevilla.es/sevilla/mercado-alza 0 1234977036.html (consulta: 2/12/2018).

Pérez, M. (2019, 23 de enero): Andalucía consolida los treinta millones de turistas pese al Brexit y los bajos precios de la competencia, El Mundo, https://www. elmundo.es/andalucia/2019/01/23/5c48958efc6c83 98568b468d.html (consulta: 2/2/2019).

Roelofsen, M. \& MincA, C. (2018): The Superhost. Biopolitics, home and community in the Airbnb dream-world of global hospitality. Geoforum, no. 91, 170-181.

https://doi.org/10.1016/j.geoforum.2018.02.021

RomÁn MÁrquez, A. (2018): El nuevo Decreto andaluz sobre viviendas particulares de uso turístico. Análisis a la luz de la agenda europea para la economía colaborativa. Cuadernos de Turismo, no. 41, 591-613.

Rodríguez, R. (2010): La política de vivienda en España en el contexto europeo. Deudas y retos. Revista INVI, vol. 25, n. ${ }^{\circ} 69,125-159$.

Troitiño VinUesA, M. A. (1998): Turismo y desarrollo sostenible en ciudades históricas. Ería, no. 47, 211-227.

Vinuesa Angulo, J. \& Martín Cortés, B. (2013): La (sobre)dimensión del crecimiento residencial en Madrid. El planeamiento urbanístico como coartada. Documents d'Anàlisi Geogràfica, vol. 59, no. 1, 51-74

VIVES-MIRÓ, S. \& RuLLAN, O. (2014): La apropiación de las rentas del suelo en la ciudad neoliberal española. Boletín de la Asociación de Geógrafos Españoles, no. $65,387-408$.

- (2017): Desposesión de vivienda por turistización? Revalorización y desplazamiento en el centro histórico de Palma (Mallorca). Revista de Geografía Norte Grande, no. 67, 53-71. 
Wachsmuth, D. \& Weisler, A. (2018): Airbnb and the rent gap: Gentrification through the sharing economy. Environment and Planning A, vol. 50, no. $6,1147-1170$.

https://doi.org/10.1177/0308518X18778038
YRIGOY, I. (2019): Rent gap reloaded: Airbnb and the shift from residential to touristic rental housing in the Palma Old Quarter in Mallorca. Urban Studies, vol. 56 , no. $13,2709-2726$.

https://doi.org/10.1177/0042098018803261 